Article

\title{
Measurement Research on the Decoupling Effect of Industries' Carbon Emissions-Based on the Equipment Manufacturing Industry in China
}

\author{
Lu Wan *, Zi-Long Wang and Jhony Choon Yeong Ng \\ Department of Economics and Management, Nanjing University of Aeronautics and Astronautics, \\ Nanjing 211106, China; wangzilong@nuaa.edu.cn (Z.-L.W.); jhonycyng@nuaa.edu.cn (J.C.Y.N.) \\ * Correspondence: karenalu@126.com; Tel.: +86-159-5053-5059 \\ Academic Editor: Luca Chiaraviglio \\ Received: 15 July 2016; Accepted: 17 October 2016; Published: 8 November 2016
}

\begin{abstract}
Economic development usually leads to increased energy consumption, which in turn will result in an increase in carbon emissions. To break the relationship between economic development and carbon emissions, scholars have turned their attention to the phenomenon of decoupling. In this paper, we studied the decoupling relationship between carbon emissions and economic growth of the equipment manufacturing industry in China from 2000 to 2014. We adapted the LMDI decomposition method, and we used the Tapio decoupling evaluation model to analyze our data. We found that the decoupling relationship between carbon emissions and economic growth of China's equipment manufacturing industry is weak, which indicates the industry is experiencing faster economic growth than carbon emission growth. We found the economic output is the factor that has the strongest influence on the industry's carbon emission, and energy consumption intensity has the strongest relationship with the decoupling of economic growth and carbon emission. The indicators of the industry's decoupling-effort are all less than 1.0, which indicates that the industry is in the state of weak decoupling, and we also observed an annual decreasing trend in the industry's indicators. Toward the end of this paper, we used the Grey forecasting model to predict the decoupling relationship between carbon emission and economic growth for 2015-2024, and we discussed the implications of our research.
\end{abstract}

Keywords: equipment manufacturing industry; carbon emission; economic growth; decoupling effect

\section{Introduction}

As global warming becomes worse, scholars have started to explore ways to achieve low carbon economic growth $[1,2]$. In recent years, the decoupling method has gained more scholarly attention in the sustainable economy literature [3-5]. The term decoupling has its root in Physics. It refers to the diminishing of the relationship between two or more interdependent variables [6]. The concept was introduced by the Organization for Economic Cooperation and Development (OECD) to public policy, economic, and environmental research at the end of the 20th century [7]. In the sustainable economy literature, decoupling refers to the reduction of a region's carbon emissions without causing negative impact on the region's economic growths. The decoupling literature has three limitations. First, decoupling is usually studied at the national or regional level, and there is a lack of research conducted at the industrial level [4]. Caneghem et al. analyzed the decoupling of environmental effects and economic growth in the Flemish industrial sector from 1995 to $2006[8,9]$. Several international organizations including the EU and OECD have joined Sweden and a handful of other nations to adopt consumption-based research perspectives [10]. Their findings suggest average consumption-based emissions are $11 \%$ higher than production emissions in the EU 27 [11] and 16\% higher among OECD 
countries. This lack of scholarly attention to industrial level phenomena has added difficulties to the attribution of the causes for pollution as scholars have limited means to determine the contribution of each industry to carbon emissions when such high level data are used. For example, the carbon emission contribution of the service industry is definitely much lesser than that of heavy industry and thus it would make little sense aggregate the data from these two industries to the national level during analyses. Second, scholars have tended to use the decoupling index method or the Tapio model when they are analyzing the relationship between carbon emission and economic growth. Zhang [12] introduced the decoupling indexes of energy sources and environmental pressure, and decoupling was also divided into absolute decoupling and relative decoupling according to its effect. This method was also used by Freitas and Kaneko [13] to study the relationship between carbon emissions and economic growth in England in 2004-2009, and then they pointed out that the relationship between carbon emissions and economic growth in 2009 was one of absolute decoupling. Climent and Pardo [4] used the Taipo decoupling indicator to investigate the causal relationship between energy use and Spanish economic growth. Chiou-Wei et al. [14] examined the relationship between energy consumption and economic growth using both linear and nonlinear Granger causality tests for a sample of Asian newly industrialized countries along with the US. Salim et al. (2008) examined the short-run and the long-run causal relationship between energy consumption and output in six non-OECD Asian developing countries. The limitation of these methods is that the results produced by such analyses provide limited information on the cause of the observed carbon emission-economic growth relationship. That is why, while we can know whether a region's economy is decoupled from carbon emissions, we do not know much about the factors that have led to this fact. Third, scholars studying decoupling have tended to over-focus on historical data [15]. A. Nicholas et al. examined the relationship between coal consumption and economic growth for 25 OECD countries within a multivariate panel framework over the 1980-2005 period. The decoupling index was used to examine the decoupling effect between carbon emissions and economic growth in Jiangsu Province (China) during 1995-2009, and it was found that carbon emissions and economic growth demonstrated an absolute decoupling effect in 1997 and 2001, no decoupling effect during 2003-2005, and a relative decoupling effect in the remaining periods [16]. There has been a stable cross-sectional relationship between energy use per capita and per capita income with an elasticity of energy use with respect to income of less than unity over the last 40 years [17]. A result of this approach is that while we are able to know what has happened, we do not know much about what we should do in the future. This has limited the empirical implications of the findings presented in the literature.

In view of the limitations of the decoupling literature, we aimed to make three contributions in this study. First, we aimed to demonstrate the advantages of conducting decoupling research on the industrial level. We propose that when decoupling research is conducted on the industrial level, we would be able to discern the factors that contribute to a region's carbon emissions better than when we use more macro-level data, thus enabling us to formulate future carbon reduction policies with greater accuracy. Second, we aimed to make improvements on the Tapio method to contribute an analytical strategy that researchers can use to better understand the factors that contribute to an industry's carbon emission. We introduced the decomposition method of the logarithmic mean Divisia index (LMDI) to the Tapio model to segregate the carbon emission of an industry into its contributing factors, and we used the decoupling effort index to calculate the magnitude of impact that each factor has on the decoupling index of an industry. Third, we aimed to adopt a more proactive approach toward decoupling studies by giving decoupling projection more focus. We based our decoupling forecast on the grey system theory, and we used the grey forecasting model to predict the trends of carbon emission and economic growth that we used in our calculations.

Towards these ends, we conducted our current research on the China's equipment manufacturing industry. China has experienced many years of double digit economic growths at the expense of its environment [18]. In 2008 it surpassed the United States to become the world largest carbon dioxide emitting country, and its carbon dioxide emissions had reached 9.21 billion tons in 2012 (accounting for 
$26.7 \%$ of global emissions) [19]. To curb this negative trend, the Chinese government had announced their intention to cut the country's carbon emission by $60 \%-65 \%$ by the year 2030 (down from its 2005 carbon emission) [20]. In China, the equipment manufacturing industry is one of its biggest carbon dioxide emitting industry sectors. Hence, we chose the Chinese equipment manufacturing industry as the focus of our research because it is one of the most polluting industries in the biggest carbon dioxide-creating country.

In the following pages, we first review the literature to provide a brief overview of our research focuses. Then, we discuss our analytical strategy by presenting the equations that we use for the series of analyses that follow, and also the sources of our data. After presenting the results of our research, we end our paper with our recommendations for future research and policies.

The literature on decoupling mainly focuses on two issues: the calculation of decoupling standards to divide regions into different categories, and methodological issues regarding the estimation of decoupling standard.

First, many scholars studying decoupling effects have mainly focused their research efforts on the labeling of different regions and countries as entities that have done relatively well or worse in terms of decoupling their economic growth from adverse environmental impacts [21-23]. For example, many Chinese scholars have merely analyzed the relationship between economic growth and carbon emissions, and concluded that China is in a state of weak decoupling [24-26].

Second, many scholars tended to use traditional decoupling measures in their research. For example, Freitas [13] used a region's data on economic activity and carbon emissions to calculate its decoupling evolution and decoupling status, and Mohamed Amine Boutabba [27] studied the relationship between carbon emissions, economic growth and energy consumption using the Granger causality method. One common characteristic of such studies is that the authors tend to use economic growth and decoupling standard models to calculate the evolution of the relationship between the two factors [28].

In recent years, some scholars have tried to innovate in their analytical strategy, however, they have mainly focused their efforts in refining the processes which they use to classify a region's decoupling status, and they tend to not go beyond the decoupling classification standard that they propose. For example, Lu Wang and Yue [29] used the IGT and IeGTX methods to analyze the relationship between $\mathrm{SO}_{2}$ emission and decoupling index, and they proposed that regional decoupling effect can be classified into three categories: absolutely decoupled, relatively decouples, and non-decoupled.

The main problem of these approaches that scholars adopt is that they tend to over-focus on the "big picture", neglecting the fact that these data were aggregated from industrial data, which in turn were aggregated from the specific factors of production. Although we can know from the results of such studies whether a region has an acceptable level of decoupling standard, we do not know much about the factors that contribute to the figures that we see. The use of such high level data has not only over-simplified the study of the contributing factors of a region's decoupling effect, it has also limited the capacity of the researcher to zero-in to "culprits" that have caused a region to exhibit a poor decoupling index in order to design policies that could effectively improve the region's decoupling index.

Evidences from recent studies indicate that the prevailing analytical strategy that is adopted by many researchers may be problematic. For example, Bithas and Kalimeris [30] recently re-estimated the energy-economic growth decoupling effect of the world by including global data on the physiology and dimensionality of economic goods. They found that the results of their research were worse than those in the literature calculated based on the traditional approach that uses energy/GDP ratio. Csereklyei and Stern [17] studied global energy consumption by using the evolution of energy use approach instead of the traditional pollution emission approach. In view of these limitations of the literature, we pose the following research question: What are the factors that influence a region's decoupling standard? 


\section{Model}

\subsection{Decoupling Effect Measurement Model}

The two main methods used to measure carbon emissions are the decoupling index and the Tapio decoupling model.

\subsubsection{Decoupling Index}

Decoupling index analyzes the decoupling relationship between energy consumption and economic growth. It is calculated by using:

$$
D_{f}=1-\frac{(E P / D F)_{t}}{(E P / D F)_{0}}
$$

where $D_{f}$ is the decoupling factor, which range is $(-\infty, 1]$; EP is the index for environmental pressure, we use $\mathrm{CO}_{2}$ emissions to represent $E P ; D F$ is the index for driving force, we use GDP to represent it. The subscripts 0 and $t$ indicate base period and reporting period respectively. When the growth rate of $\mathrm{CO}_{2}$ emissions is greater than the growth rate of GDP, such that $D_{f} \in(0,1]$, a decoupling relationship is present (which will in turn be further divided into "relative decoupling" or "absolute decoupling"). On the other hand, when the growth rate of $\mathrm{CO}_{2}$ emissions is less than the growth rate of GDP, such that $D_{f} \in(-\infty, 0]$, it is considered to be in a state of non-decoupling.

\subsubsection{Tapio Decoupling Model}

The Tapio decoupling model is an elastic analysis first proposed by Tapio for his research on the volume of European transportation and decoupling standards of $\mathrm{CO}_{2}$ during 1970-2001 [31]. The Tapio decoupling model uses the flexibility index to analyze the decoupling relationship between environment pressure and economic growth, and it can be represented by the following equation:

$$
\gamma_{\left(\mathrm{CO}_{2}, G D P\right)}=\frac{\Delta C \mathrm{O}_{2}}{\mathrm{CO}_{2}} / \frac{\Delta G D P}{G D P}
$$

where $\gamma_{\mathrm{CO}_{2}, \mathrm{GDP}}$ is the elasticity of decoupling indicators between carbon emissions and economic growth. It represents the impact of $\mathrm{CO}_{2}$ emissions to economic growth. Table 1 shows the eight states of decoupling proposed by Tapio.

Table 1. Eight Different State of Decoupling according to Tapio.

\begin{tabular}{ccccc}
\hline & State & Environmental Pressure & Economic Growth & Elasticity: $\gamma$ \\
\hline \multirow{2}{*}{ Negative } & Expansionary Negative Decoupling & $(0,+\infty)$ & $(0,+\infty)$ & $(1.2,+\infty)$ \\
Decoupling & Strong Negative Decoupling & $(0,+\infty)$ & $(-\infty, 0)$ & $(-\infty, 0)$ \\
& Weak Negative Decoupling & $(-\infty, 0)$ & $(-\infty, 0)$ & $(0,0.8)$ \\
\hline \multirow{3}{*}{ Decoupling } & Weak Decoupling & $(0,+\infty)$ & $(0,+\infty)$ & $(0,0.8)$ \\
& Strong Decoupling & $(-\infty, 0)$ & $(0,+\infty)$ & $(-\infty, 0)$ \\
& Recession Decoupling & $(-\infty, 0)$ & $(-\infty, 0)$ & $(1.2,+\infty)$ \\
\hline \multirow{2}{*}{ Link } & Growing Link & $(0,+\infty)$ & $(0,+\infty)$ & $(0.8,1.2)$ \\
& Recession Link & $(-\infty, 0)$ & $(-\infty, 0)$ & $(0.8,1.2)$ \\
\hline
\end{tabular}

Tapio introduced the elasticity theory into the decoupling indicator, and subdivided the eight different states of decoupling into expansionary negative decoupling, strong negative decoupling, weak negative decoupling, weak decoupling, strong decoupling, recession decoupling, growing link, recession link. Decoupling occurs when the carbon intensity decreases $(\gamma<0)$. Otherwise, it is negative decoupling $(\gamma>0)$. According to the rate of GDP, the rate of change in the carbon intensity $\left(\triangle \mathrm{CO}_{2} / \mathrm{CO}_{2}\right)$, and the decoupling index of GDP and carbon emissions $(\gamma)$, eight different possibilities can be identified. 
Compared to the traditional decoupling method, the Tapio decoupling model is essentially an elastic analysis method, as its advantages are not affected by changes of statistical dimensions, and one or more intermediate variables can be introduced to the decomposition of decoupling index.

\subsection{Measurement Model of Carbon Emissions}

The energy consumption of the equipment manufacturing industry is driven by the consumption of coal, oil and natural gas, and carbon dioxide is the main pollutant produced by such energy consumption. Therefore, this paper chooses carbon emissions to represent environmental pressure index of energy consumption, and we choose GDP as an index driver of economic growth. We calculate carbon emissions in ten thousand tons of standard coal units by using the expression:

$$
C=\sum_{i=1}^{n} C_{i}=\sum_{i=1}^{n} H_{i} \cdot \delta_{i}
$$

where $C$ = Carbon emission of equipment manufacturing (in ten thousand tons of standard coal); $C_{i}=$ all kinds of energy carbon emissions; $H_{i}=$ energy consumption of energy $i ; \delta_{i}=$ coefficient of carbon emissions of energy $i ; n=$ Types of energy.

Due to the limitations in the available data, we focused our current research on the carbon emissions of coal, coke, gasoline, diesel and natural gas. The carbon emissions coefficients are shown in Table 2. Energy coefficient of carbon emissions refers to the number of carbon emissions produced per unit energy use.

Table 2. The energy coefficient of carbon emissions.

\begin{tabular}{cccccc}
\hline Energy & Coal & Coke & Gasoline & Diesel & Gas \\
\hline Carbon Emissions Coefficient & 0.7559 & 0.8550 & 0.5538 & 0.5921 & 0.4483 \\
\hline \multicolumn{6}{c}{ Data Sources: Intergovernmental Panel on Climate Change [32]. }
\end{tabular}

\section{Data}

According to China's national economy industry classification and code (GB/T 4754-2011), the equipment manufacturing industry is made up of seven major groups, which can be further divided into 209 sub-groups. The seven major groups are: metal manufacturing, general equipment manufacturing, professional equipment manufacturing, transportation equipment manufacturing, electric machinery and equipment manufacturing, electronic and communication equipment manufacturing, and instrument and office appliance manufacturing. DP measures the value added of industry. The sources of our data are: the China Statistical Yearbook and China Energy Statistical Yearbook for the period of 2000-2014.

\section{Empirical Analysis of Decoupling Effect of Industries' Carbon Emissions Measure}

\subsection{Decoupling of Carbon Emissions Measure}

Utilizing Equations (2) and (3), we divided the annual statistics of China's equipment manufacturing industry into different levels of decoupling (see Table 3). We observe an annual decline in the decoupling elasticity for 2005-2008. The economy was growing, but at the same time, energy carbon emissions were also increasing at a rate lower than GDP growth. This improvement in the industry's energy efficiency might be due to the implementation of public policies such as the "Opinions of the State Council on Accelerating the Development of the Equipment Manufacturing Industry", which provided financial support to business owners in the industry. 
Table 3. The decoupling condition of carbon emissions and GDP of equipment manufacturing industry in China period of 2001-2014.

\begin{tabular}{ccccc}
\hline Time & $\mathrm{SCO}_{2} / \mathrm{CO}_{2}$ & $\begin{array}{c}\Delta \text { GDP/GDP } \\
\text { (One Hundred Million Yuan) }\end{array}$ & $\gamma$ & Decoupling Condition \\
\hline $2000-2001$ & 0.072 & 0.159 & 0.453 & Weak Decoupling \\
$2001-2002$ & 0.122 & 0.217 & 0.562 & Weak Decoupling \\
$2002-2003$ & 0.118 & 0.343 & 0.345 & Weak Decoupling \\
$2003-2004$ & 0.159 & 0.480 & 0.332 & Weak Decoupling \\
$2004-2005$ & 0.081 & 0.116 & 0.698 & Weak Decoupling \\
$2005-2006$ & 0.130 & 0.275 & 0.474 & Weak Decoupling \\
$2006-2007$ & 0.108 & 0.282 & 0.381 & Weak Decoupling \\
$2007-2008$ & 0.079 & 0.235 & 0.336 & Weak Decoupling \\
$2008-2009$ & 0.070 & 0.046 & 1.522 & Expansionary Negative Decoupling \\
$2009-2010$ & 0.051 & 0.195 & 0.259 & Weak Decoupling \\
$2010-2011$ & 0.068 & 0.167 & 0.407 & Weak Decoupling \\
$2011-2012$ & -0.034 & 0.044 & -0.771 & Strong Decoupling \\
$2012-2013$ & -0.005 & 0.076 & -0.068 & Strong Decoupling \\
$2013-2014$ & -0.024 & 0.088 & -0.273 & Strong Decoupling \\
\hline
\end{tabular}

Data Sources: China statistical yearbook and China energy statistical yearbook.

On the other hand, expansionary negative decoupling was observed in the data for 2008-2009. A potential explanation for this observation is the adverse impact on the industry caused by the 2007 global financial crisis. To alleviate the situation, the Chinese government implemented market expanding policies to increase the demand for the industry's products. The public intervention turned out to be effective, and the decoupling condition improved to become weak decoupling in 2009-2010, and it further improved to become strong decoupling in 2011-2014.

To have a clearer view on the contributing factors to the observations made above, we further divided our industrial data into its seven-component industries (see Table 4). The terms $\gamma_{1}, \gamma_{2}, \gamma_{3}, \gamma_{4}, \gamma_{5}, \gamma_{6}, \gamma_{7}$ refer to the decoupling elasticity indexes of metal manufacturing, general equipment manufacturing, professional equipment manufacturing, transportation equipment manufacturing, electric machinery and equipment manufacturing, electronic and communication equipment manufacturing, and instrument and office appliance manufacturing, respectively.

Table 4. The Calculation Results of Decoupling Elasticity Indexes among Equipment Manufacturing Industries in China during 2000-2014.

\begin{tabular}{cccccccc}
\hline Time & $\gamma_{\mathbf{1}}$ & $\gamma_{\mathbf{2}}$ & $\gamma_{\mathbf{3}}$ & $\gamma_{\mathbf{4}}$ & $\gamma_{\mathbf{5}}$ & $\gamma_{\mathbf{6}}$ & $\gamma_{\mathbf{7}}$ \\
\hline $2000-2001$ & 0.279 & 0.480 & -0.467 & 0.441 & -1.109 & 0.891 & 0.679 \\
$2001-2002$ & 0.555 & 0.363 & -0.684 & 0.278 & 0.430 & 0.884 & 0.531 \\
$2002-2003$ & -0.614 & -0.010 & 0.699 & -1.132 & -0.374 & 0.077 & 0.421 \\
$2003-2004$ & 0.073 & 0.350 & 1.105 & 0.421 & 0.575 & 0.541 & -0.255 \\
$2004-2005$ & 0.077 & 1.622 & -0.033 & 0.334 & -0.114 & -0.098 & -0.624 \\
$2005-2006$ & 0.138 & 0.239 & 0.124 & 0.139 & 0.105 & 0.134 & 0.144 \\
$2006-2007$ & 0.083 & 0.297 & 0.051 & 0.066 & 0.011 & 0.152 & 0.076 \\
$2007-2008$ & 0.338 & -0.255 & -0.029 & 0.193 & 0.686 & 0.355 & 0.556 \\
$2008-2009$ & 0.251 & 0.665 & 0.954 & 0.420 & -0.060 & -1.142 & 0.514 \\
$2009-2010$ & -0.368 & 0.117 & 0.782 & 0.382 & 0.462 & 0.172 & 0.403 \\
$2010-2011$ & -0.666 & 0.481 & -0.775 & -0.117 & -0.681 & -1.291 & -1.232 \\
$2011-2012$ & 0.698 & -0.683 & -0.447 & -0.727 & -1.186 & -1.224 & -0.523 \\
$2012-2013$ & 0.396 & -0.585 & -0.437 & -0.004 & 0.158 & 0.077 & 0.018 \\
$2013-2014$ & 0.482 & -0.463 & -0.249 & -0.831 & 0.319 & 0.142 & 0.201 \\
\hline
\end{tabular}

Based on the decoupling elasticity indexes calculated, we divided the seven sub-industries into its respective decoupling state categories (see Table 5). The decoupling states are divided based on Table 1 (the eight different state of decoupling according to Tapio). 
Table 5. The decoupling condition among equipment manufacturing industries in China.

\begin{tabular}{|c|c|c|c|c|c|c|c|}
\hline Time & $\gamma_{1}$ State & $\gamma_{2}$ State & $\gamma_{3}$ State & $\gamma_{4}$ State & $\gamma_{5}$ State & $\gamma_{6}$ State & $\gamma_{7}$ State \\
\hline 2000-2001 & $\begin{array}{c}\text { Weak } \\
\text { Decoupling }\end{array}$ & $\begin{array}{c}\text { Weak } \\
\text { Decoupling }\end{array}$ & $\begin{array}{c}\text { Strong } \\
\text { Decoupling }\end{array}$ & $\begin{array}{c}\text { Weak } \\
\text { Decoupling }\end{array}$ & $\begin{array}{c}\text { Strong } \\
\text { Decoupling }\end{array}$ & $\begin{array}{l}\text { Growing } \\
\text { Link }\end{array}$ & $\begin{array}{c}\text { Weak } \\
\text { Decoupling }\end{array}$ \\
\hline 2001-2002 & $\begin{array}{c}\text { Weak } \\
\text { Decoupling }\end{array}$ & $\begin{array}{c}\text { Weak } \\
\text { Decoupling }\end{array}$ & $\begin{array}{c}\text { Strong } \\
\text { Decoupling }\end{array}$ & $\begin{array}{c}\text { Weak } \\
\text { Decoupling }\end{array}$ & $\begin{array}{c}\text { Weak } \\
\text { Decoupling }\end{array}$ & $\begin{array}{l}\text { Growing } \\
\text { Link }\end{array}$ & $\begin{array}{c}\text { Weak } \\
\text { Decoupling }\end{array}$ \\
\hline 2002-2003 & $\begin{array}{c}\text { Strong } \\
\text { Decoupling }\end{array}$ & $\begin{array}{c}\text { Strong } \\
\text { Decoupling }\end{array}$ & $\begin{array}{c}\text { Weak } \\
\text { Decoupling }\end{array}$ & $\begin{array}{c}\text { Strong } \\
\text { Decoupling }\end{array}$ & $\begin{array}{c}\text { Strong } \\
\text { Decoupling }\end{array}$ & $\begin{array}{c}\text { Weak } \\
\text { Decoupling }\end{array}$ & $\begin{array}{c}\text { Weak } \\
\text { Decoupling }\end{array}$ \\
\hline 2003-2004 & $\begin{array}{c}\text { Weak } \\
\text { Decoupling }\end{array}$ & $\begin{array}{c}\text { Weak } \\
\text { Decoupling }\end{array}$ & $\begin{array}{l}\text { Growing } \\
\text { Link }\end{array}$ & $\begin{array}{c}\text { Weak } \\
\text { Decoupling }\end{array}$ & $\begin{array}{c}\text { Weak } \\
\text { Decoupling }\end{array}$ & $\begin{array}{c}\text { Weak } \\
\text { Decoupling }\end{array}$ & $\begin{array}{c}\text { Strong } \\
\text { Decoupling }\end{array}$ \\
\hline 2004-2005 & $\begin{array}{c}\text { Weak } \\
\text { Decoupling }\end{array}$ & $\begin{array}{l}\text { Expansionary } \\
\text { Negative } \\
\text { Decoupling }\end{array}$ & $\begin{array}{c}\text { Strong } \\
\text { Decoupling }\end{array}$ & $\begin{array}{c}\text { Weak } \\
\text { Decoupling }\end{array}$ & $\begin{array}{c}\text { Strong } \\
\text { Decoupling }\end{array}$ & $\begin{array}{c}\text { Strong } \\
\text { Decoupling }\end{array}$ & $\begin{array}{c}\text { Strong } \\
\text { Decoupling }\end{array}$ \\
\hline 2005-2006 & $\begin{array}{c}\text { Weak } \\
\text { Decoupling }\end{array}$ & $\begin{array}{c}\text { Weak } \\
\text { Decoupling }\end{array}$ & $\begin{array}{c}\text { Weak } \\
\text { Decoupling }\end{array}$ & $\begin{array}{c}\text { Weak } \\
\text { Decoupling }\end{array}$ & $\begin{array}{c}\text { Weak } \\
\text { Decoupling }\end{array}$ & $\begin{array}{c}\text { Weak } \\
\text { Decoupling }\end{array}$ & $\begin{array}{c}\text { Weak } \\
\text { Decoupling }\end{array}$ \\
\hline 2006-2007 & $\begin{array}{c}\text { Weak } \\
\text { Decoupling }\end{array}$ & $\begin{array}{c}\text { Weak } \\
\text { Decoupling }\end{array}$ & $\begin{array}{c}\text { Weak } \\
\text { Decoupling }\end{array}$ & $\begin{array}{c}\text { Weak } \\
\text { Decoupling }\end{array}$ & $\begin{array}{c}\text { Weak } \\
\text { Decoupling }\end{array}$ & $\begin{array}{c}\text { Weak } \\
\text { Decoupling }\end{array}$ & $\begin{array}{c}\text { Weak } \\
\text { Decoupling }\end{array}$ \\
\hline 2007-2008 & $\begin{array}{c}\text { Weak } \\
\text { Decoupling }\end{array}$ & $\begin{array}{c}\text { Strong } \\
\text { Decoupling }\end{array}$ & $\begin{array}{c}\text { Strong } \\
\text { Decoupling }\end{array}$ & $\begin{array}{c}\text { Weak } \\
\text { Decoupling }\end{array}$ & $\begin{array}{c}\text { Weak } \\
\text { Decoupling }\end{array}$ & $\begin{array}{c}\text { Weak } \\
\text { Decoupling }\end{array}$ & $\begin{array}{c}\text { Weak } \\
\text { Decoupling }\end{array}$ \\
\hline 2008-2009 & $\begin{array}{c}\text { Weak } \\
\text { Decoupling }\end{array}$ & $\begin{array}{c}\text { Weak } \\
\text { Decoupling }\end{array}$ & $\begin{array}{l}\text { Growing } \\
\text { Link }\end{array}$ & $\begin{array}{c}\text { Weak } \\
\text { Decoupling }\end{array}$ & $\begin{array}{c}\text { Strong } \\
\text { Decoupling }\end{array}$ & $\begin{array}{c}\text { Strong } \\
\text { Decoupling }\end{array}$ & $\begin{array}{c}\text { Weak } \\
\text { Decoupling }\end{array}$ \\
\hline 2009-2010 & $\begin{array}{c}\text { Strong } \\
\text { Decoupling }\end{array}$ & $\begin{array}{c}\text { Weak } \\
\text { Decoupling }\end{array}$ & $\begin{array}{c}\text { Weak } \\
\text { Decoupling }\end{array}$ & $\begin{array}{c}\text { Weak } \\
\text { Decoupling }\end{array}$ & $\begin{array}{c}\text { Weak } \\
\text { Decoupling }\end{array}$ & $\begin{array}{c}\text { Weak } \\
\text { Decoupling }\end{array}$ & $\begin{array}{c}\text { Weak } \\
\text { Decoupling }\end{array}$ \\
\hline 2010-2011 & $\begin{array}{c}\text { Strong } \\
\text { Decoupling }\end{array}$ & $\begin{array}{c}\text { Weak } \\
\text { Decoupling }\end{array}$ & $\begin{array}{c}\text { Strong } \\
\text { Decoupling }\end{array}$ & $\begin{array}{c}\text { Strong } \\
\text { Decoupling }\end{array}$ & $\begin{array}{c}\text { Strong } \\
\text { Decoupling }\end{array}$ & $\begin{array}{c}\text { Strong } \\
\text { Decoupling }\end{array}$ & $\begin{array}{c}\text { Strong } \\
\text { Decoupling }\end{array}$ \\
\hline 2011-2012 & $\begin{array}{c}\text { Weak } \\
\text { Decoupling }\end{array}$ & $\begin{array}{c}\text { Strong } \\
\text { Decoupling }\end{array}$ & $\begin{array}{c}\text { Strong } \\
\text { Decoupling }\end{array}$ & $\begin{array}{c}\text { Strong } \\
\text { Decoupling }\end{array}$ & $\begin{array}{c}\text { Strong } \\
\text { Decoupling }\end{array}$ & $\begin{array}{c}\text { Strong } \\
\text { Decoupling }\end{array}$ & $\begin{array}{c}\text { Strong } \\
\text { Decoupling }\end{array}$ \\
\hline 2012-2013 & $\begin{array}{c}\text { Weak } \\
\text { Decoupling }\end{array}$ & $\begin{array}{c}\text { Strong } \\
\text { Decoupling }\end{array}$ & $\begin{array}{c}\text { Strong } \\
\text { Decoupling }\end{array}$ & $\begin{array}{c}\text { Strong } \\
\text { Decoupling }\end{array}$ & $\begin{array}{c}\text { Weak } \\
\text { Decoupling }\end{array}$ & $\begin{array}{c}\text { Weak } \\
\text { Decoupling }\end{array}$ & $\begin{array}{c}\text { Weak } \\
\text { Decoupling }\end{array}$ \\
\hline 2013-2014 & $\begin{array}{c}\text { Weak } \\
\text { Decoupling }\end{array}$ & $\begin{array}{c}\text { Strong } \\
\text { Decoupling }\end{array}$ & $\begin{array}{c}\text { Strong } \\
\text { Decoupling }\end{array}$ & $\begin{array}{c}\text { Strong } \\
\text { Decoupling }\end{array}$ & $\begin{array}{c}\text { Weak } \\
\text { Decoupling }\end{array}$ & $\begin{array}{c}\text { Weak } \\
\text { Decoupling }\end{array}$ & $\begin{array}{c}\text { Weak } \\
\text { Decoupling }\end{array}$ \\
\hline
\end{tabular}

In general, the decoupling state of carbon emissions and GDP in the metal manufacturing industry was steady during 2000-2014. The decoupling effect was weak during 2000-2001, and it improved to become strong decoupling during 2002-2003, indicating effective attempts in cutting carbon emissions. However, the decoupling state deteriorated to weak decoupling during 2003-2009, indicating that the industry's energy consumption growth has outpaced its GDP growth. The decoupling state then improved to become strong decoupling again from 2009-2011.

On the other hand, the decoupling state of the general equipment industry is not stable during 2000-2014. In 2000, the decoupling state of the industry was weak. It then becomes strong decoupling in 2003, weak decoupling in 2004, and then expansionary negative decoupling in 2005. In other words, the growth rate of the industry's energy carbon emission was faster than its GDP growth rate, indicating that its energy utilization efficiency is becoming worse over the years. However, the industry's decoupling state improved to strong decoupling during 2011-2014. A potential explanation to this finding is the government had implemented industrial adjustment policies and carbon emission reduction policies during this period of time, and the improvements observed might be a result of public policy compliance. Analysis of the data on the professional equipment manufacturing industry indicates that it had strong decoupling during 2000-2002. However, it deteriorated to weak decoupling during 2002-2003, which then improved to growing link in 2003-2004, indicating that the growing economic growth was achieved with large amount of energy consumption and pollution. The industry's decoupling state then improved to strong decoupling until 2008. The global financial crisis had taken its toll on the market demand for the industry, and caused the decoupling state of the 
industry to reduce to weak decoupling. That is, the decoupling state of the professional equipment manufacturing industry had phased characteristics.

The decoupling state of the transportation equipment manufacturing industry was stable from 2000-2014. It improved from weak decoupling during 2000-2001 to become strong decoupling in 2010-2014. The improvement can be attributed to the benefits brought upon by technological advances experienced by the industry over the years, and also the structural changes caused by the government's industrial policies.

The decoupling state of the electric machinery and equipment manufacturing industry was unstable. It alternated between weak decoupling and strong decoupling over the years, indicating that the industry's energy carbon emission growth rate was higher than its GDP growth rate.

The decoupling state of the electronic and communication equipment manufacturing industry experienced significant fluctuations over the years. During 2000-2002, the industry's development created strong pressures on its carbon emissions. However, as the Chinese government increased their financial support on the industry's development over the years, the decoupling state of the industry had improved since 2004 as indicated by its lower level of carbon emission per unit GDP. Nevertheless, the decoupling state of the industry was not very stable, and it alternated between strong decoupling and weak decoupling.

The decoupling state of the instrument and office appliance manufacturing industry was relatively stable during 2000-2014, and its decoupling elastic index was decreasing annually. The industry had strong decoupling in 2003-2005 and 2010-2012, and it had weak decoupling for the other years. The industry had achieved rapid GDP growth with reduced total energy consumption. This indicates the industry was performing well in terms of carbon emission reduction.

\subsection{Factor-Separating of Carbon Emission Decoupling}

In 1997, Ang and Choi put forward a refined Divisia index method using logarithmic mean weight functions, which could settle well the residual and "zero value" problems and satisfy other conditions of "perfect decomposition approaches" simultaneously. This method as the early decomposition form of LMDI [33]. Then Ang et al. extended the above approach which was based on decomposition of an aggregate index, and proposed another refined Divisa index method based on logarithmic mean weight functions and decomposition of a different quantity in 1998 [34]. The appellations LMDI I and LMDI II first appeared in 2001, when Ang and Liu presented a new energy decomposition method, called the LogMean Divisia Index Method I (LMDI I) [35]. The logarithmic mean Divisia index (LMDI) method has the desirable properties of perfect decomposition and is consistent in aggregation. The method is a widely accepted analytic tool to identify the relative impacts of different factors [36-38]. There are the logarithmic terms in the LMDI formula, complications arise when the data set contains zero values. We used the method of Divisia index to analyze the carbon emission of the equipment manufacturing into energy efficiency, industry structure, the level of economic development and labor of equipment manufacturing industry. From the perspective of economy, the equation to calculate the energy consumption of carbon emissions should be:

$$
C=\sum_{i} \frac{C_{i}}{E} \cdot \frac{E}{G D P} \cdot \frac{G D P}{P} \cdot P=\sum_{i} A_{i} \cdot I \cdot M \cdot P
$$

where $i=1,2, \ldots 5$, $(i$ represents energy, respectively the raw coal, coke, gasoline, diesel and natural gas); $C_{i}=$ carbon emissions; $E=$ energy consumption of equipment manufacturing; $P=$ the average number of labor of equipment manufacturing industry; $A_{i}=C_{i} / E$ represents energy consumption structure, that is, carbon intensity of energy structure; $I=E / G D P$ represents energy intensity of GDP; $M=G D P / P$ represents regional GDP per capita. 
Equation (4) can be expressed as product of four factors (effect of energy structure, energy intensity effect, economic output effect and population scale effect), and the change of carbon emission of energy consumption depending on the four factors. Using the LMDI method, the model can be written as:

$$
\Delta C=C_{t}-C_{0}=\Sigma A_{i, t} \cdot I_{t} \cdot M_{t} \cdot P_{t}-\Sigma A_{i, 0} \cdot I_{0} \cdot M_{0} \cdot P_{0}=\Delta C_{A}+\Delta C_{I}+\Delta C_{M}+\Delta C_{P}+\Delta C_{\varphi}
$$

Where $\Delta C_{A}=$ carbon intensity of energy structure; $\Delta C_{I}=$ energy intensity of GDP; $\Delta C_{M}=$ regional GDP per capita; $\Delta C_{P}=$ population scale; $\Delta C_{\phi}=$ decomposition allowance.

By decomposition and natural logging Equation (4), we obtained:

$$
\frac{d C}{d t}=\sum_{i} \frac{A_{i}}{d t} \cdot I \cdot M \cdot P+\sum_{i} A_{i} \cdot \frac{d I}{d t} \cdot M \cdot P+\sum_{i} A_{i} \cdot I \cdot \frac{d M}{d t} \cdot P+\sum_{i} A_{i} \cdot I \cdot M \cdot \frac{d P}{d t}
$$

When both sides of Equation (6) are divided by $C$, we obtain:

$$
\frac{1}{C} \cdot \frac{d C}{d t}=\sum_{i} \frac{1}{A_{i}} \cdot \frac{d A_{i}}{d t} \cdot \frac{A_{i}}{C} \cdot I \cdot M \cdot P+\sum_{i} A_{i} \cdot \frac{1}{I} \cdot \frac{d I}{d t} \cdot \frac{I}{C} \cdot M \cdot P+\sum_{i} A_{i} \cdot I \cdot \frac{1}{M} \cdot \frac{d M}{d t} \cdot \frac{M}{C} \cdot P+\sum_{i} A_{i} \cdot I \cdot M \cdot \frac{1}{P} \cdot \frac{d P}{d t} \cdot \frac{P}{C}
$$

By definite integration of Equation (7), we obtain:

$$
\int \frac{d \ln C}{d t} d t=\sum_{i} \frac{A_{i} \cdot I \cdot M \cdot P}{E} \cdot\left(\frac{d \ln A_{i}}{d t}+\frac{d \ln I}{d t}+\frac{d \ln M}{d t}+\frac{d \ln P}{d t}\right) d t
$$

$T_{i}=\frac{A_{i} \cdot I \cdot M \cdot P}{E},(8)$ can be expressed in the following function:

$$
\begin{gathered}
K=\frac{C_{t}-C_{0}}{\ln \left(C_{t} / C_{0}\right)} \text { thus }\left\{\begin{array}{l}
\Delta C_{A}=\sum_{i} K \ln \frac{A_{t}}{A_{0}} \\
\Delta C_{I}=\sum_{i} K \ln \frac{I_{t}}{I_{0}} \\
\Delta C_{M}=\sum_{i} K \ln \frac{M_{t}}{M_{0}} \\
\Delta C_{P}=\sum_{i} K \ln \frac{P_{t}}{P_{0}}
\end{array}\right. \\
\Delta C_{\varphi}=\Delta C-\left(\Delta C_{A}+\Delta C_{I}+\Delta C_{M}+\Delta C_{P}\right)=C_{t}-C_{0}-\sum_{i} K\left(\ln \frac{A_{i, t}}{A_{i, 0}}+\ln \frac{I_{t}}{I_{0}}+\ln \frac{M_{t}}{M_{0}}+\ln \frac{P_{t}}{P_{0}}\right) \\
=C_{t}-C_{0}-\sum_{i} K \ln \frac{A_{i, t} I_{t} M_{t} P_{t}}{A_{i, 0} I_{0} M_{0} P_{0}}=C_{t}-C_{0}-\sum_{i} K \ln \frac{C_{t}}{C_{0}}=0
\end{gathered}
$$

Therefore, carbon emissions can be expressed as:

$$
\Delta C=C_{t}-C_{0}=\Delta C_{A}+\Delta C_{I}+\Delta C_{M}+\Delta C_{P}
$$

Substituting into the decoupling model of carbon emissions and economic growth, we obtain:

$$
\begin{aligned}
& \gamma_{\left(\mathrm{CO}_{2}, G D P\right)}=\frac{\Delta \mathrm{CO}_{2}}{C \mathrm{O}_{2}} / \frac{\Delta G D P}{G D P}=\Delta C \mathrm{CO}_{2} \cdot \frac{G D P}{\mathrm{CO}_{2} \cdot \Delta G D P}=\left(\Delta C_{A}+\Delta C_{I}+\Delta C_{M}+\Delta C_{P}\right) \cdot \frac{G D P}{C O_{2} \cdot \Delta G D P} \\
& =\frac{\Delta C_{A} / C}{\Delta G D P / G D P}+\frac{\Delta C_{I} / C}{\Delta G D P / G D P}+\frac{\Delta C_{M} / C}{\Delta G D P / G D P}+\frac{\Delta C_{P} / C}{\Delta G D P / G D P}=\gamma_{A}+\gamma_{I}+\gamma_{M}+\gamma_{P}
\end{aligned}
$$

Based on Equation (12), we observe that the decoupling elasticity index of carbon emissions and economic growth of equipment manufacturing $\gamma_{\left(\mathrm{CO}_{2}, \mathrm{GDP}\right)}$ can be decomposed into the energy structure decoupling elasticity, energy intensity decoupling elasticity, economic output decoupling elasticity and population of the region, indicated by $\gamma_{A}, \gamma_{I}, \gamma_{M}, \gamma_{P}$. According to the Equation (12), we obtained the results shown in Table 6 using the data of 2000-2014.

Based on Table 6, we see the variation of carbon emissions of equipment manufacturing industry is greatly influenced by the energy consumption intensity and economic output. This means the rigid demand of energy growth in the equipment manufacturing industry is great, and the economic growth of the equipment manufacturing is achieved at the expense of the environment. In general, economic output is the biggest cause of carbon emissions in the equipment manufacturing industry of China. 
$\Delta C_{I}$ has negative and greatest impact on the carbon emissions of equipment manufacturing in 2014 [carbon emissions $=3782.27\left(10^{4} \mathrm{t}\right)$ ]. It means that energy efficiency will be improved, and this is beneficial to carbon emissions reduction. Compared with $\Delta C_{I}$ and $\Delta C_{M}$, carbon emissions are less affected by factors of energy structure and population. Because the equipment manufacturing industry in China is greatly affected by the external economy, the consumption structure is simple, and the major consumption of energy is coal and oil.

Table 6. The calculation results of carbon emissions factorization and the decoupling elasticity indexes for the period of 2000-2014.

\begin{tabular}{ccccccccc}
\hline Time & $\Delta \boldsymbol{C}_{\boldsymbol{A}}$ & $\gamma_{\boldsymbol{A}}$ & $\Delta \boldsymbol{C}_{\boldsymbol{I}}$ & $\gamma_{\boldsymbol{I}}$ & $\Delta \boldsymbol{C}_{\boldsymbol{M}}$ & $\gamma_{\boldsymbol{M}}$ & $\Delta \boldsymbol{C}_{\boldsymbol{P}}$ & $\gamma_{\boldsymbol{P}}$ \\
\hline 2000-2001 & -137.72 & -0.148 & -159.46 & -0.171 & 352.70 & 0.379 & -49.19 & -0.053 \\
$2001-2002$ & -284.53 & -0.128 & -334.10 & -0.151 & 728.99 & 0.329 & -4.73 & -0.002 \\
$2002-2003$ & -574.76 & -0.143 & -707.84 & -0.176 & 1131.62 & 0.281 & 192.21 & 0.048 \\
$2003-2004$ & -608.16 & -0.096 & -1312.97 & -0.207 & 1657.62 & 0.261 & 652.48 & 0.103 \\
$2004-2005$ & -638.42 & -0.088 & -1440.47 & -0.198 & 1843.08 & 0.254 & 814.46 & 0.112 \\
$2005-2006$ & -804.36 & -0.089 & -1777.97 & -0.197 & 2266.93 & 0.251 & 1063.62 & 0.118 \\
$2006-2007$ & -1008.74 & -0.094 & -2155.63 & -0.201 & 2632.77 & 0.245 & 1342.07 & 0.125 \\
$2007-2008$ & -1141.33 & -0.094 & -2522.58 & -0.208 & 2811.64 & 0.232 & 1745.94 & 0.144 \\
$2008-2009$ & -1137.22 & -0.088 & -2758.49 & -0.213 & 3172.44 & 0.245 & 1805.66 & 0.140 \\
$2009-2010$ & -1567.86 & -0.096 & -2947.44 & -0.180 & 3590.93 & 0.219 & 2166.33 & 0.132 \\
$2010-2011$ & -1725.82 & -0.097 & -3194.99 & -0.179 & 4047.10 & 0.227 & 2142.56 & 0.120 \\
$2011-2012$ & -1752.73 & -0.101 & -3272.27 & -0.189 & 4056.65 & 0.234 & 2013.60 & 0.116 \\
$2012-2013$ & -1591.02 & -0.088 & -3644.99 & -0.201 & 4460.52 & 0.246 & 2329.32 & 0.129 \\
$2013-2014$ & -1683.21 & -0.126 & -3782.27 & -0.273 & 4620.65 & 0.256 & 2521.56 & 0.142 \\
\hline
\end{tabular}

Based on Figure 1, we derived the following conclusions:

(1) The decoupling elasticity coefficients of carbon energy structure were negative and have strong decoupling. Before 2006, the absolute values of carbon energy structure were reduced annually, and the absolute value was on the increasing trend after 2006. This is because of the economic policies implemented by the Chinese government to adjust the industry's structure in order to stimulate economic growth rapidly. Therefore, the absolute values of elastic index of carbon energy structure were increased, but then declined until 2013.

(2) The decoupling elasticity coefficients of economic output were in weak decoupling state, and had positive an effect on the increase in total carbon emissions during 2000-2014. In general, other than 2008, the decoupling elasticity coefficients of economic output were decreasing. The reason is that it was affected by the financial crisis in 2008, the growth rate of GDP was falling, equipment manufacturing enterprises suffered badly and the energy consumption growth was reduced.

(3) Energy intensity was in the strong decoupling state. Energy consumption intensity was negative and the varied range of decoupling elasticity coefficients of energy intensity fluctuated between 0.15 and 0.21 . It can be seen that the energy efficiency of equipment manufacturing was higher. Therefore, when carbon emissions of equipment manufacturing was reduced to a certain extent, the impact was not great for decoupling of carbon emission and GDP by reducing per capita of GDP. This can only be achieved by reducing energy intensity, and the decrease of energy intensity relied on the Chinese government implements policies such as developing low carbon energy and adjusting the industrial structure.

(4) The decoupling elasticity coefficients of population scale present strong decoupling during 2000-2002. They were in a weak decoupling state during the 2002-2003 period, and the decoupling indexes were increasing annually. The maximum decoupling index was 0.1438 in 2008. The reduced decoupling elasticity coefficients of population scale, were achieved only by improving the quality of equipment manufacturing employees and greatly enhancing the employees' productivity, in order to reduce carbon emissions by increasing output per worker. In total, the sharp increase of population size plays a much smaller role in the carbon emissions. 


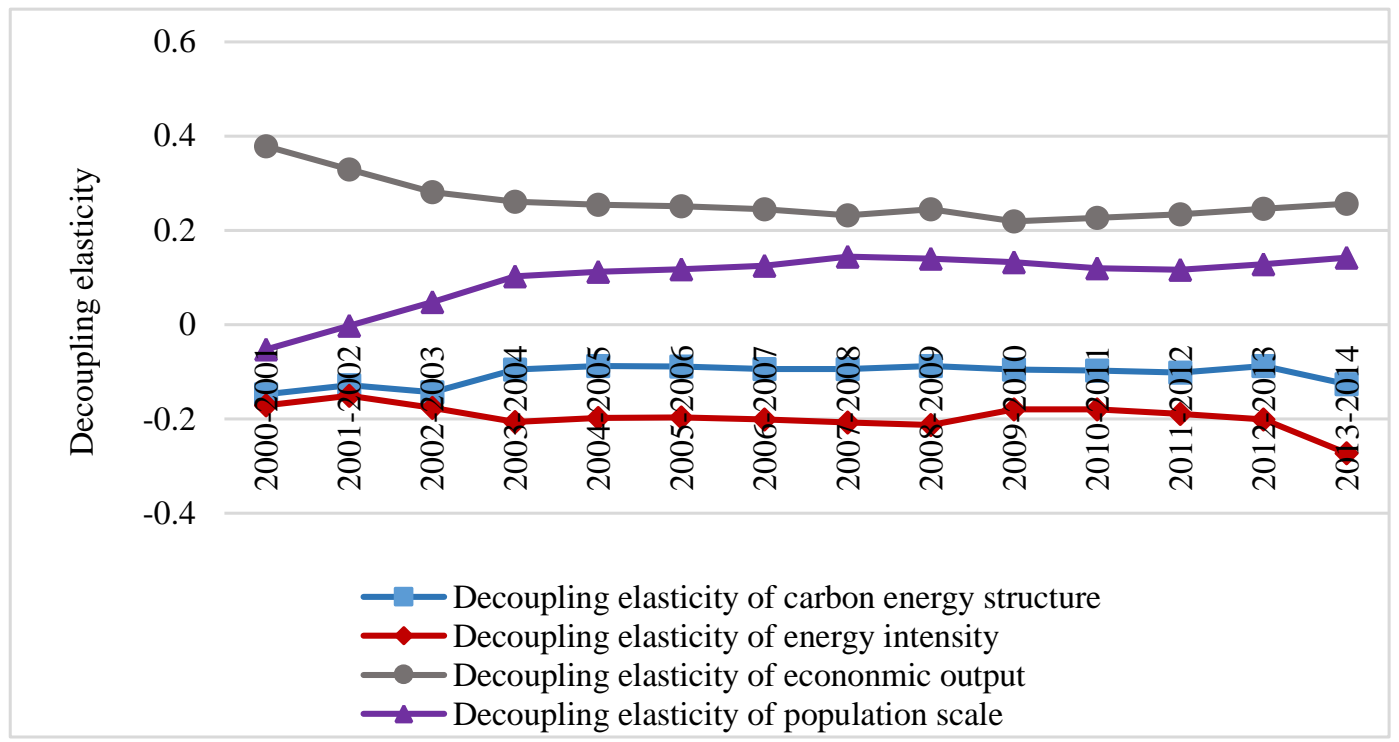

Figure 1. Carbon emissions factorization and the decoupling elasticity indexes of the equipment manufacturing industry from 2000 to 2014.

\subsection{Carbon Emissions Decoupling-Effort}

The objective of decoupling-effort is to reduce carbon emissions by the government policies and measures to adjust the industrial structure, improving energy efficiency. We can break down the antecedents of carbon emissions $(\Delta C)$ into the effect of energy structure $\left(\Delta C_{A}\right)$, energy intensity effect $\left(\Delta C_{I}\right)$, the effect of economic output $\left(\Delta C_{M}\right)$, and the effect of population scale $\left(\Delta C_{P}\right)$. We set value of decoupling-effort is $\Delta C_{Z}$, the equation can be expressed in the following function:

$$
\Delta C_{Z}=\Delta C-\Delta C_{M}=\Delta C_{A}+\Delta C_{I}+\Delta C_{P}
$$

If the set index of decoupling-effort is $\lambda$, which represents the degree of decoupling-effort during $0-t$, we obtain:

$$
\lambda=-\Delta C_{Z} / \Delta C_{M}
$$

As shown in Table 6, when the economic output was more than 0, we obtain:

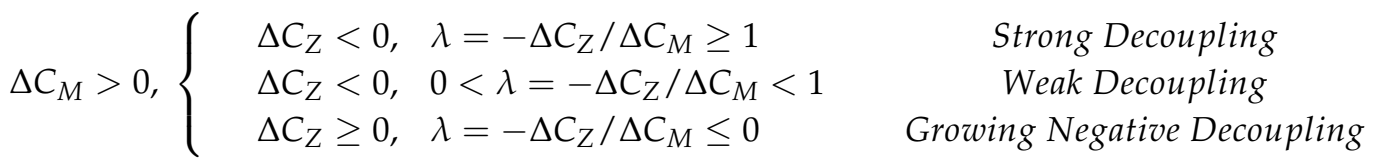

Inserting the data of equipment manufacturing period of 2000-2014 into Equation (15), we can get results shown in Table 7.

Based on Table 7, the values of decoupling-effort were negative in equipment manufacturing during 2000-2014, and the indexes of decoupling-effort were less than 1, indicating that it was in a state of weak decoupling. This indicates that the equipment manufacturing had high consumption and carbon emissions, and heavy industry is preferred in China. As the pressure of economic growth can cause more carbon emissions, the other three indicators were negative. The energy intensity effect had the highest value. The improvement of energy efficiency is the most critical factor that influences the difference effect in decoupling-effort of carbon emissions. 
Table 7. Comparison between the decoupling-effort indicators of the equipment manufacturing industry in China during the period 2000-2014.

\begin{tabular}{cccc}
\hline Time & $\Delta \boldsymbol{C}_{\boldsymbol{Z}}$ & $\lambda$ & Decoupling Condition \\
\hline $2000-2001$ & -346.38 & 0.98 & Weak Decoupling \\
$2001-2002$ & -623.36 & 0.86 & Weak Decoupling \\
$2002-2003$ & -1090.40 & 0.96 & Weak Decoupling \\
$2003-2004$ & -1268.64 & 0.77 & Weak Decoupling \\
$2004-2005$ & -1264.43 & 0.69 & Weak Decoupling \\
$2005-2006$ & -1518.71 & 0.67 & Weak Decoupling \\
$2006-2007$ & -1822.3 & 0.69 & Weak Decoupling \\
$2007-2008$ & -1917.97 & 0.68 & Weak Decoupling \\
$2008-2009$ & -2090.05 & 0.66 & Weak Decoupling \\
$2009-2010$ & -2348.96 & 0.65 & Weak Decoupling \\
$2010-2011$ & -2778.26 & 0.69 & Weak Decoupling \\
$2011-2012$ & -3011.40 & 0.74 & Weak Decoupling \\
$2012-2013$ & -2906.70 & 0.65 & Weak Decoupling \\
$2013-2014$ & -2943.92 & 0.64 & Weak Decoupling \\
\hline
\end{tabular}

\subsection{Forecast Model}

The Grey systems theory, established initially by Julong Deng in 1982, focuses on the study of problems where the sample is small and the information poor [39]. It deals with uncertain systems with partially known information which is generated, excavated and extracted from what is available. Grey models have been successfully used in several fields as energy or regional economics among others. The Grey system theory principles constitute the base of Grey forecasting models [40]. The Grey forecasting model presents interesting advantages, especially for temporally limited information scenarios. It will be able to characterize an unknown system given relative little discrete data such as only four observations [41].

In addition, in Grey systems theory, the most common model is the Grey Model with First Order Differential Equation and one Variable model GM(1,1). The $\operatorname{GM}(1,1)$ requires only a few number of historical data and is used to predict exponential signals in real time. In this paper, we use $\operatorname{GM}(1,1)$ to predict carbon emissions and economic growth of equipment manufacturing during 2015-2024 to predict the trends of carbon emissions and economic growth in the equipment manufacturing sector for the next 10 years. Testing the original sequences during 2000-2014 for smoothness, we found that the original carbon emissions and economic growth sequences are smooth sequences, in which the accumulating generation sequence has an accurate index law (see Figures 2 and 3).

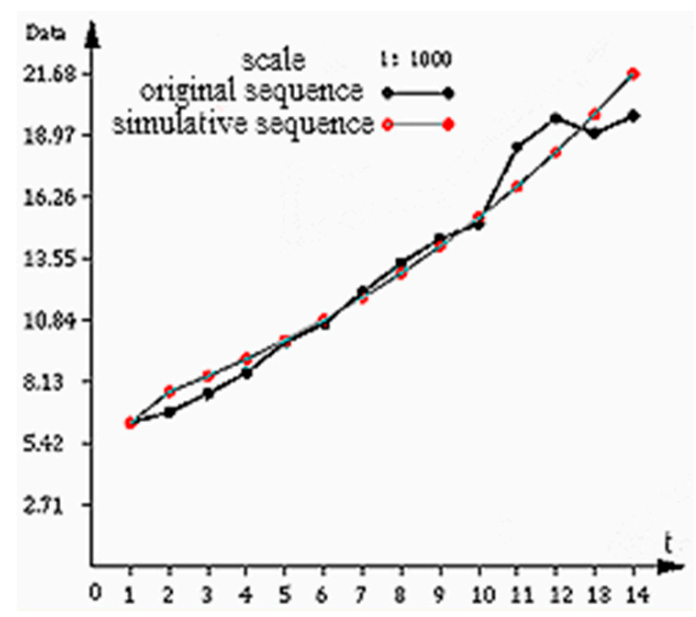

Figure 2. Contrast of carbon primitive data and simulated data curve. 


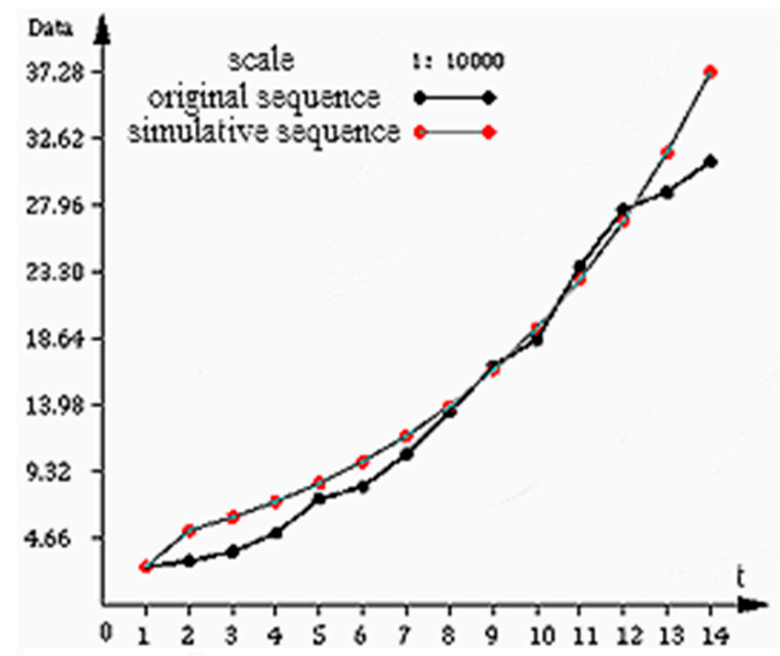

Figure 3. Comparison between GDP primitive data and the simulated data curve.

Based on Figures 2 and 3, we observed that the results are satisfactory and accurate. According to the calculation results of average GM $(1,1)\left[\frac{d x^{(1)}}{d t}+a x^{(1)}=b\right]$ and time response $\left[\hat{x}^{(1)}(k)=\left(x^{(0)}(1)-\right.\right.$ $\left.\left.\frac{b}{a}\right) e^{-a(k-1)}+\frac{b}{a}\right]$ by using the Tapio model, we obtained the decoupling condition of carbon emissions and GDP for 2014-2023 (Table 8).

Table 8. The decoupling condition of carbon emissions and GDP of the equipment manufacturing industry period of 2015-2024.

\begin{tabular}{ccc}
\hline Time & $\gamma$ & Decoupling Condition \\
\hline $2014-2015$ & 0.224 & Weak Decoupling \\
$2015-2016$ & 0.562 & Weak Decoupling \\
$2016-2017$ & 0.628 & Weak Decoupling \\
$2017-2018$ & 0.648 & Weak Decoupling \\
$2018-2019$ & 0.716 & Weak Decoupling \\
$2019-2020$ & 0.785 & Weak Decoupling \\
$2020-2021$ & 0.794 & Weak Decoupling \\
$2021-2022$ & 0.844 & Growing Link \\
$2022-2023$ & 0.901 & Growing Link \\
$2023-2024$ & 1.133 & Growing Link \\
\hline
\end{tabular}

The forecast results indicate that equipment manufacturing had weak decoupling, and the decoupling indexes will increase annually after 2015. If the current industrial development trends continue, the decoupling state will deteriorate further. Growing links will appear in 2021. That is, economic growth and carbon emissions will be increasing at the same time. However, the growth rate of carbon emission will be greater than the growth rate of GDP, and the equipment manufacturing industry will be facing tremendous pressure to save energy. In order to develop a low-carbon economy, the Chinese government should implement active measures and corresponding policies to prevent the impact of economic growth to energy consumption.

\section{Conclusions and Recommendations}

\subsection{Theoretical Implications}

Based on our research, we found that the decoupling relationship between the carbon emission of the equipment manufacturing industry and economic growth was weakly decoupling, and the state was unstable. There was big differences between the decoupling indexes of the seven major groups of 
the equipment manufacturing industry, and the trend of strong decoupling industries was on the rise. Compared with the previous research, this paper changed the conventional approach that restricts the research object to the national, regional or industry level. This method cannot know the decoupling state of subsections of certain industries, so it can't analyze the fractional industry impact on the whole country or kinds of industries accurately, and cannot grasp the development of an industry precisely.

We divided the industry into its constituting factors, and we fixed the equipment manufacturing industry as the research object. Based on the research, we found that the professional equipment manufacturing is most likely to be affected by the external environment. This is because it is a typical downstream demand-dull industry, and it was closely related to the state's macro-policy, fixed-asset investment and development of the downstream industry. Compared to the growth rate of GDP in electric machinery and equipment manufacturing, the growth rate of carbon emissions was higher, indicating the energy efficiency was low. This is because the industry products need high levels of tech-intensiveness.

China is still at the development stage, and it needs to increase its technological investment to meet the needs of the industry's development. Electronic and communication equipment manufacturing as a typical example of high-tech industries and equipment manufacturing industry, showed the most significant improvement of decoupling state. In recent years, the Chinese government has supported the development of the industry from the perspectives of talent cultivation and capital investment to rapidly boost the development of the industry. On the whole, the decoupling state of instrument and office appliance manufacturing was the most stable and in weak decoupling, with the decoupling index reducing gradually. This paper is good for analyzing the decoupling effect impact on manufacturing industries more clearly and specifically.

We have also adapted the LMDI decomposition method and decoupling-effort model to accurately analyze the factors of the decoupling state. We divided it into four categories which described the effect of economic output, followed by the energy intensity effect. We found that the increase in the economic output was the most important factor for the carbon emission growth. We can lay out the development direction of industry accurately by analyzing the factors affecting the mechanism of action of the decoupling effect, and thoroughly "decoupling" between energy consumption and economic growth.

Previous studies were based on the analysis of existing data and they did not attempt to forecast. Immediately after serious environmental pollution problems appeared, the government or enterprises took action to cure these environmental problems. That is, a treatment after pollution pattern. The innovation of the article lies in introducing the Gray forecasting model and forecast data effectively. Using econometric models it is difficult to forecast rationally because of the incomplete China Statistical Yearbook data. However, the Grey forecasting model can forecast in the short-term effectively with less data. According to the forecast, the rigid demand of China's equipment manufacturing industry will be large in the coming decade, and the industry development relies on energy-intensive activities and high pollutant generation so the industrial structure needs to be optimized. Therefore, this paper proposes some corresponding counter-development measures according to the development of the industry.

\subsection{Implications of Research}

Due to the limitations of technology and resource endowment, the Chinese equipment manufacturing industries are faced with problems such as unreasonable industrial structure, low excess capacity, lack of high capacity, and the fact the heavy industry accounts for a large proportion in the national economy. These will limit the industry development. Therefore, the main way to reduce the carbon emissions of equipment manufacturing is only by upgrading the industry structure and improving energy efficiency. Besides, the energy consumption of the equipment manufacturing industry had relied heavily on coal, oil and other fossil fuels, and their consumption compared to new energy consumption is larger, which is not conducive to low-carbon development. Therefore, tax incentives, financial subsidies and other fiscal policies should be implemented for the development 
of the new energy industry in order to optimize the energy structure and hold back rapid growth of carbon emissions from the source. Finally, the government should give full play to the functions of guidance, supervision, incentive, encourage enterprise to study the emissions reduction experience of foreign enterprises and strictly implement low-carbon emission standards. At the same time, the government should work out and improve the related laws and regulations, injecting new vigor into the development of the low-carbon economy.

\section{Conclusions}

To meet the lower carbon emissions objectives, we studied the decoupling relationship between carbon emissions and economic growth of the equipment manufacturing industry in China from 2000 to 2014 by using the LMDI decomposition method and the Tapio decoupling evaluation model. We used the Grey forecasting model to predict the decoupling relationship between carbon emissions and economic growth for 2015-2024. We found that the decoupling relationship between carbon emissions and economic growth of China's equipment manufacturing industry is weak, which indicates the industry is experiencing faster economic growth than carbon emission growth. We found the economic output is the factor that has the strongest influence on the industry's carbon emission, and energy consumption intensity has the strongest relationship with the decoupling of economic growth and carbon emission. China's equipment manufacturing industry needs to optimize its industrial structure. The study only forecast the relationship between carbon emissions and economic growth of equipment manufacturing, and we conducted no further analysis on the decoupling state of other kinds of industries. In the future, scholars can study the decoupling effect in the field of industrial structure. We will continue to improve the relevant theoretical research about the decoupling relationships between carbon emissions and economic growth.

Acknowledgments: I'm grateful to the anonymous reviewers for their valuable suggestions which improved the paper. This research was supported by the National Natural Science Foundation of China (Grant No. 71373005); Fundamental Research Funds for the Central Universities (Grant No. NR2015002; NR2016302; NR2015063, 1009-YAH15053); Teaching Reformation and Construction Project of Nanjing University of Aeronautics and Astronautics (Grant No. 201501JG09004); The Key Project of Social Science Research in Colleges and Universities in Jiangsu Province (Grant No. 2016ZDIXM006); Innovation Funds for Nanjing University of Aeronautics and Astronautics (Grant No. kfjj20160110).

Author Contributions: For research articles with several authors, a short paragraph specifying their individual contributions must be provided. The following statements should be used "Lu Wan conceived and designed the experiments; Lu Wan performed the experiments; Zi-Long Wang and Jhony Choon Yeong Ng analyzed the data; Lu Wan, Zi-Long Wang contributed reagents/materials/analysis tools; Lu Wan, Zi-Long Wang and Jhony Choon Yeong Ng wrote the paper". Authorship must be limited to those who have contributed substantially to the work reported.

Conflicts of Interest: The authors declare no conflict of interest.

\section{References}

1. Böhringer, C.; Lange, A. On the design of optimal grandfathering schemes for emission allowances. Eur. Econ. Rev. 2005, 49, 2041-2055. [CrossRef]

2. Carmona, R.; Hinz, J. Risk-neutral models for emission allowance prices and option valuation. Manag. Sci. 2011, 57, 1453-1468. [CrossRef]

3. Kveiborg, O.; Fosgerau, M. Explaining the decoupling of freight traffic growth and economic growth. Transp. Policy 2007, 14, 39-48. [CrossRef]

4. Climent, F.; Pardo, A. Decoupling factors on the energy-output linkage: The Spanish case. Energy Policy 2007, 35, 522-528. [CrossRef]

5. Sorrell, S.; Lehtonen, M.; Stapleton, L.; Pujol, J.; Champion, T. Decoupling of road freight energy use from economic growth in the United Kingdom. Energy Policy 2012, 41, 84-97. [CrossRef]

6. Li, X.S.; Qu, F.T.; Guo, Z.X.; Jiang, D.M.; Pan, Y.Q.; Chen, X.L. Decoupling between urban and rural construction land. China Popul. Resour. Environ. 2008, 18, 179-184. 
7. Chen, B.M.; Du, H.L. Analyzing decoupling relationship between arable land occupation and GDP growth. Resour. Sci. 2006, 28, 36-42.

8. Van Caneghem, J.; Block, C.; Van Hooste, H.; Vandecasteele, C. Eco-efficiency trends of the Flemish industry: Decoupling of environmental impact from economic growth. Clean Prod. 2010, 18, 1349-1357. [CrossRef]

9. Warr, B.; Ayres, R.; Eisenmenger, N.; Krausmann, F.; Schandl, H. Energy use and economic development: A comparative analysis of useful work supply in Austria, Japan, the United Kingdom and the US during 100 years of economic growth. Ecol. Econ. 2010, 69, 1904-1917. [CrossRef]

10. Csutora, M.; Mózner, Z. Rethinking Kyoto compliance from a consumption-based perspective China-EU. Coop. Sustain. Econ. 2012, 26, 177-200.

11. $\mathrm{CO}_{2}$ Emissions Production-Based Accounting vs. Consumption: Insights from the World Database. Available online: http:/ /www.wiod.org/conferences/groningen/paper_Boitier.pdf (accessed on 15 July 2016).

12. Zhang, Z.X. Decoupling China's carbon emissions increase from economic growth: An economic analysis and policy implications. World Dev. 2000, 28, 739-752. [CrossRef]

13. Freitas, L.C. Decomposing the decoupling of $\mathrm{CO}_{2}$ emissions and economic growth in Brazil. Ecol. Econ. 2011, 6, 1459-1469. [CrossRef]

14. Chiou-Wei, S.Z.; Chen, C.F.; Zhu, Z. Economic growth and energy consumption revisited-evidence from linear and non-linear Granger causality. Energy Econ. 2008, 30, 3063-3076. [CrossRef]

15. Nicholas, A.; James, E.P. Coal consumption and economic growth: Evidence from a panel of OECD countries. Energy Policy 2010, 38, 1353-1359.

16. Wang, W.W.; Liu, R.; Zhang, M.; Li, H.N. Decomposing the decoupling of energy related $\mathrm{CO}_{2}$ emissions and economic growth in Jiangsu province. Energy Sustain. Dev. 2013, 17, 62-71. [CrossRef]

17. Csereklyei, Z.; Rubio-Varas, M.D.M.; Stern, D.I. Energy and economic growth: The stylized facts. Energy 2016, 37, 223-255. [CrossRef]

18. Van Ruijven, B.; Urban, F.; Benders, R.M.J.; Moll, H.C.; Van der Sluijs, J.P.; De Vries, B.; Van Vuuren, D.P. Modeling energy and development: An evaluation of models and concepts. World Dev. 2009, 36, 2801-2821. [CrossRef]

19. Statistical Review of World Energy. Available online: http://www.bp.com/en/global/corporate/energyeconomics/statistical-review-of-world-energy.html (accessed on 23 June 2016).

20. China Makes Efforts to Fight Climate Change. Available online: http://en.ce.cn/main/latest/201512/13/ t20151213_7516747.shtml (accessed on 23 June 2016).

21. Diakoulaki, D.; Mandaraka, M. Decomposition analysis for assessing the progress in decoupling industrial growth from $\mathrm{CO}_{2}$ emissions in the EU manufacturing sector. Energy Econ. 2007, 29, 636-664. [CrossRef]

22. Lu, I.J.; Lin, S.J.; Lewis, C. Decomposition and decoupling effects of carbon dioxide emission from highway transportation in Taiwan, Germany, Japan and South Korea. Energy Policy 2007, 35, 3226-3235. [CrossRef]

23. Martínez, C.I.P. Energy efficiency developments in the manufacturing industries of Germany and Colombia, 1998-2005. Energy Sustain. Dev. 2009, 131, 89-101. [CrossRef]

24. Cao, G.X.; Liu, Y.Q.; Zhou, Y.; Zhou, J.Y. Study on spatial econometrics of carbon emission decoupling in the development of Chinese manufacturing industry-Analysis of four major economic zones. Sci. Technol. Manag. Res. 2015, 12, 224-228.

25. Zhang, Y.Q.; Liu, C.G.; Bai, W.G. Research of low-carbon economy development in Shandong province-based on decoupling effect and panel cointegration of analysis. Soft Sci. 2015, 29, 48-52.

26. Zheng, L.X.; Zhou, M. Decoupling and driving factors analysis between the relationship of carbon emissions and economic growth in China. J. Ind. Tech. Econ. 2015, 9, 19-25.

27. Boutabba, M.A. The impact of financial development, income, energy and trade on carbon emissions: Evidence from the Indian economy. Econ. Model. 2014, 40, 33-41. [CrossRef]

28. Andreoni, V.; Galmarini, S. Decoupling economic growth from carbon dioxide emissions: A decomposition analysis of Italian energy consumption. Energy 2012, 44, 682-691. [CrossRef]

29. Lu, Z.W.; Wang, H.M.; Yue, Q. Decoupling indicators: Quantitative relationships between resource use, waste emission and economic growth. Resour. Sci. 2011, 33, 2-9.

30. Bithas, K.; Kalimeris, P. Re-estimating the decoupling effect: Is there an actual transition towards a less energy-intensive economy? Energy 2013, 51, 78-84. [CrossRef]

31. Tapio, P. Toward a theory of coupling: Degrees of decoupling in the EU and the case of road traffic in Finland between 1970 and 2001. Transp. Policy 2005, 12, 137-151. [CrossRef] 
32. IPCC-Intergovernmental Panel on Climate Change. Available online: www.ipcc.ch (accessed on 15 July 2016).

33. Ang, B.W.; Choi, K.H. Decomposition of aggregate energy and gas emission intensities for industry: A refined Divisia index method. Energy 1997, 18, 59-73. [CrossRef]

34. Ang, B.W.; Zhang, F.Q.; Choi, K.H. Factorizing changes in energy and environmental indicators through decomposition. Energy 1998, 23, 489-495. [CrossRef]

35. Ang, B.W.; Liu, F.L. A new energy decomposition method: Perfect in decomposition and consistent in aggregation. Energy 2001, 26, 537-548. [CrossRef]

36. Xu, S.C.; He, Z.X.; Long, R.Y. Factors that influence carbon emissions due to energy consumption in China: Decomposition analysis using LMDI. Appl. Energy 2014, 127, 182-193. [CrossRef]

37. Song, M.L.; Guo, X.; Wu, K.Y.; Wang, G.X. Driving effect analysis of energy-consumption carbon emissions in the Yangtze River Delta region. J. Clean. Prod. 2015, 103, 620-628. [CrossRef]

38. Yan, X.; Fang, Y.P. $\mathrm{CO}_{2}$ emissions and mitigation potential of the Chinese manufacturing industry. J. Clean. Prod. 2015, 103, 759-773. [CrossRef]

39. Deng, J.L. Control problems of grey systems. Syst. Control Lett. 1982, 1, 288-294.

40. Hsu, L.C.; Wang, C.H. Forecasting integrated circuit output using multivariate grey model and grey relational analysis. Expert Syst. Appl. 2009, 36, 1403-1409. [CrossRef]

41. Shi, Q.; Zhao, J. Development Report of Chinese Industries; China ZhiGong Publishing House: Beijing, China, 1999.

(C) 2016 by the authors; licensee MDPI, Basel, Switzerland. This article is an open access article distributed under the terms and conditions of the Creative Commons Attribution (CC-BY) license (http:/ / creativecommons.org/licenses/by/4.0/). 